\title{
Estratégias de ensino voltadas à produção escrita dos estudantes com deficiência intelectual
}

\author{
Teaching strategies the written production of students with intellectual \\ disability
}

\author{
Ana Paula Zaboroski, Jáima Pinheiro de Oliveira \\ Universidade Estadual Paulista (UNESP)
}

\begin{abstract}
Resumo
O objetivo foi identificar as estratégias de ensino voltadas à produção escrita dos estudantes com deficiência intelectual. A busca sistematizada das teses e dissertações foi realizada na base de dados da Biblioteca Digital Brasileira de Teses e Dissertações (BDTD), publicadas entre 2008 a 2017 no idioma Português. As pesquisas selecionadas foram categorizadas por meio da análise do conteúdo. Os resultados indicaram número restrito de pesquisas $(n=13)$ acerca desta temática. Dentre elas, 7 analisaram a utilização de programas para o ensino de leitura e escrita e 6 investigaram as estratégias de alfabetização (leitura e escrita) e letramento desenvolvidas com estes estudantes.

Palavras-chave: Educação Especial, deficiência intelectual, prática pedagógica, escrita.
\end{abstract}

\begin{abstract}
The objective was to identify teaching strategies geared to the written production of students with intellectual disabilities. The systematized search for the theses and dissertations, published between 2008 and 2017 in Portuguese, was carried out in the database of the Brazilian Digital Library of Theses and Dissertations (BDTD). The selected searches were categorized through content analysis. The results indicated a limited number of researches $(n=13)$ on this subject. Among them, 7 analyzed the use of programs for teaching reading and writing and 6 investigated literacy strategies (reading and writing) and literacy developed with these students.

Keywords: Special Education, intellectual disability, pedagogical practice, writing.
\end{abstract}

\section{Introdução}

Os estudantes públicos-alvo da Educação Especial por meio da Política Nacional inclusiva (BRASIL 2008) têm direito ao acesso, à permanência, à participação e à aprendizagem na sala de aula comum do ensino regular, recebendo o suporte do Atendimento Educacional Especializado (AEE) em todos os níveis de ensino.

Alguns estudos acerca da alfabetização de estudantes com deficiência intelectual evidenciaram que eles possuem dificuldades expressivas no desenvolvimento e aprendizagem das habilidades da leitura e da escrita (OLIVEIRA 2015, VALENTIM 2011). A pesquisa realizada por Oliveira (2015) expõe que $62,5 \%$ dos estudantes com deficiência intelectual possuem dificuldades significativas na realização dos conteúdos gerais da Língua Portuguesa. Contudo, eles também evidenciaram possibilidades de aprendizagem, principalmente com ajuda, as quais, de acordo com a autora, devem ser consideradas pelos professores a fim de impulsionar a escolarização destes estudantes.

Nesse sentido, as práticas pedagógicas sob a perspectiva inclusiva precisam utilizar recursos e desenvolver estratégias de ensino específicas que favoreçam o processo de alfabetização e escolarização destes estudantes. A pesquisa desenvolvida por Oliveira \& Ruiz (2014) concluiu que apesar de ter ocorrido alguns avanços nas ações pedagógicas e nas possibilidades de aprendizagem e desenvolvimento dos estudantes com deficiência intelectual, a produção científica nesta área e temática ainda é insuficiente.

Sendo assim, o objetivo deste estudo foi identificar os recursos e as estratégias de ensino voltadas à produção escrita dos estudantes com deficiência intelectual.

\section{Método}

A revisão sistemática da literatura (MEDRADO; GOMES; NUNES SOBRINHO, 2014) acerca da temática desta pesquisa foi realizada na base de dados da Biblioteca Digital Brasileira de Teses e Dissertações (BDTD). Os descritores indexados no Thesaurus Brasileiro da Educação utilizados foram: aprendizagem da escrita; linguagem escrita e prática pedagógica. Também foram utilizados descritores livres: escrita; recursos pedagógicos e estratégias de ensino. Todos os descritores foram combinados por meio do operador booleano AND com o descritor indexado deficiência intelectual.

A fim de refinar a busca estabelecemos três critérios: a) teses e dissertações; b) publicação entre 2008 a 2017 e c) idioma em Português. Foram consideradas na análise as teses e dissertações que investigaram as estratégias de ensino e os recursos pedagógicos voltados para a produção escrita dos estudantes com deficiência intelectual. Para tal seleção, buscamos estas 
informações no título e resumo. Foram excluídas as produções científicas que não atenderam à temática deste estudo. As temáticas das pesquisas selecionadas foram categorizadas por meio da análise de conteúdo (BARDIN, 2011), sendo identificadas duas categorias temáticas: a) utilização de programas para o ensino de leitura e escrita e b) estratégias de alfabetização (leitura e escrita) e letramento.

\section{Resultados e Discussões}

A Tabela 1 apresenta a frequência absoluta (n) das teses e dissertações encontradas, refinadas e selecionadas para a análise em cada descritor.

Tabela1.

Frequência absoluta (n) das teses e dissertações encontradas, refinadas e selecionadas para a análise

\begin{tabular}{|c|c|c|c|}
\hline \multirow[t]{2}{*}{ Descritores } & \multicolumn{3}{|c|}{ Frequência absoluta (n) } \\
\hline & Encontradas & Refinadas & Selecionadas \\
\hline $\begin{array}{ll}\text { Escrita } & \text { AND } \\
\text { Deficiência } & \\
\text { intelectual } & \end{array}$ & 26 & 13 & 10 \\
\hline Linguagem escrita & 3 & 1 & 1 \\
\hline $\begin{array}{l}\text { AND Deficiência } \\
\text { intelectual }\end{array}$ & & & \\
\hline $\begin{array}{l}\text { Aprendizagem da } \\
\text { escrita AND } \\
\text { Deficiência } \\
\text { intelectual }\end{array}$ & 1 & 1 & 1 \\
\hline $\begin{array}{l}\text { Prática pedagógica } \\
\text { AND Deficiência } \\
\text { intelectual }\end{array}$ & 40 & 32 & 1 \\
\hline $\begin{array}{l}\text { Recursos } \\
\text { pedagógicos AND } \\
\text { Deficiência } \\
\text { intelectual }\end{array}$ & 4 & 2 & 0 \\
\hline $\begin{array}{lr}\text { Estratégias } & \text { de } \\
\text { ensino } & \text { AND } \\
\text { Deficiência } & \\
\text { intelectual } & \\
\end{array}$ & 7 & 4 & 0 \\
\hline Total & 81 & 53 & 13 \\
\hline
\end{tabular}

Fonte: Dados organizados pelas autoras.

Os dados da Tabela 1 indicam que há uma frequência baixa $(n=81)$ de pesquisas voltadas às práticas pedagógicas com estudantes com deficiência intelectual. Destas produções científicas, 53 atenderam aos critérios da busca desta pesquisa, sendo 39 dissertações e 14 teses. O descritor Prática pedagógica AND Deficiência intelectual foi o que apresentou maior frequência $(n=32)$, seguido do descritor Escrita AND Deficiência intelectual com $n=13$.

Contudo, apenas 13 pesquisas foram selecionadas para a análise em razão de investigarem as estratégias de ensino e os recursos pedagógicos voltados para a produção escrita dos estudantes com deficiência intelectual. Dentre elas, 8 pesquisas são dissertações e 5 são teses.

Chamamos a atenção para o fato de que a maior frequência $(n=32)$ das pesquisas refinadas diz respeito ao descritor Prática pedagógica AND Deficiência intelectual, porém, apenas 1 pesquisa foi selecionada para a análise. Isso ocorreu devido ao fato de estas pesquisas se preocuparem em analisar outras temáticas como: as concepções docente e as práticas pedagógicas desenvolvidas acerca do processo da inclusão; avaliação da inclusão educacional; relação entre currículo e prática pedagógica; formação para docentes voltado ao processo de inclusão; avaliação da aprendizagem escolar; sistematização do atendimento educacional especializado; dentre outras.

As temáticas das pesquisas selecionadas foram categorizadas por meio da análise de conteúdo (BARDIN, 2011), sendo identificadas duas categorias temáticas: a) utilização de programas para o ensino de leitura e escrita e b) estratégias de alfabetização (leitura e escrita) e letramento, apresentadas na Tabela 2, a seguir:

Tabela 2.

Frequência absoluta (n) das pesquisas analisadas de acordo com as categorias temáticas

\begin{tabular}{lc}
\hline \multicolumn{1}{c}{ Categorias Temáticas } & $\begin{array}{l}\text { Frequência } \\
\text { absoluta (n) }\end{array}$ \\
\hline $\begin{array}{l}\text { Utilização de programas para o ensino } \\
\text { de leitura e escrita }\end{array}$ & 7 \\
$\begin{array}{l}\text { Estratégias de alfabetização (leitura e } \\
\text { escrita) e letramento }\end{array}$ & 6 \\
\hline \multicolumn{1}{c}{ Total } & $\mathbf{1 3}$ \\
\hline
\end{tabular}

Fonte: Dados organizados pelas autoras.

Os dados da Tabela 2 demonstram que 7 produções científicas descreveram sobre a utilização de programas para o ensino de leitura e escrita e, outras 6, pesquisaram as estratégias de alfabetização voltadas à leitura, escrita e letramento desenvolvidas com estudantes com deficiência intelectual.

A seguir, por meio das Tabelas 3 e 4 as referidas pesquisas serão descritas em relação aos programas ou estratégias desenvolvidas para o ensino da leitura e escrita a estes estudantes públicos-alvo da Educação Especial.

Tabela 3.

Descrição dos programas utilizados no ensino da leitura e escrita aos estudantes com deficiência intelectual

Autor/Ano Programa de ensino

Afonso Aprendendo a Ler e a Escrever em Pequenos

(2011) Passos ${ }^{\circledR}$ (ProgLeit) utilizando o Módulo 1 que ensina palavras com sílabas simples do tipo consoante-vogal.

Brito Programa para consciência fonológica. Nas (2014) atividades de rima e aliteração os estudantes tinham que marcar as imagens cujos nomes terminavam (rima) ou começavam (aliteração) com o nome da imagem em destaque. Nas atividades da consciência de palavra os estudantes tinham que falar o nome da imagem e marcar a quantidade de círculos que representava a quantidade de sílabas na palavra. Nas atividades de consciência fonêmica os estudantes recebiam formas geométricas diferentes em que cada uma representava um fonema e quando os estudantes ouvissem uma palavra com determinado fonema deveriam apontar a forma correspondente. Algumas destas atividades foram realizadas por meio do 
computador utilizando o CD "Alfabetização Fônica".

Conti Programa de leitura compartilhada, utilizando (2014) 20 livros de histórias infantis. As atividades do programa de ensino foram: realizar leitura da história selecionada pelo estudante; fazer questões que envolvessem os estudantes na história e relacionassem o que ouviam com o conhecimento prévio que têm sobre o assunto; após a leitura da história identificar o primeiro nome dos estudantes e verificar a presença das letras do seu nome em alguns títulos dos livros; identificar os nomes das histórias nas capas dos livros; registrar a história ouvida em desenho e, realizar a leitura de faz-de-conta utilizando diversos materiais (massinha de modelar, blocos de encaixe, lego, fantoches).

Freitas $\mathrm{O}$ programa de leitura foi construído no (2012) quarto estudo por meio do programa Aprendendo a Ler e a Escrever em Pequenos Passos® (ProgLeit), utilizando o Módulo 1 de ensino. O programa apresentou a cada sessão progressão gradual dos estímulos treinados por meio de palavras. As primeiras palavras foram regulares, compostas por duas sílabas do tipo consoante-vogal. Com o passar dos passos outras configurações foram introduzidas com palavras de três sílabas ou com sílabas formadas por letras isoladas e/ou com letras tendo sons diferentes. O treino de cada palavra ocorreu com foco na palavra como um todo e, em seguida, treinando as sílabas das palavras. As tarefas de treino envolviam a seleção auditivo-visual de palavras e sílabas escritas e a cópia e o ditado com construção tanto pela composição por letras quanto por sílabas.

Menzori Aprendendo a Ler e a Escrever em Pequenos (2016) Passos ${ }^{\circledR}$ (ProgLeit) utilizando o Módulo 1 que ensina palavras com sílabas simples do tipo consoante-vogal.

Oliveira Aprendendo a Ler e a Escrever em Pequenos (2010) Passos ${ }^{\circledR}$ (ProgLeit), sendo utilizados os Módulos 1 e 2 . O Módulo 1 ensina palavras simples do tipo consoante-vogal e o Módulo 2 ensina palavras com dificuldades da língua, compostas por sílabas complexas ou com dígrafos.

Santos Procedimento de ensino utilizando o software (2012) educativo Mestre $®$. O procedimento de ensino foi organizado em cinco etapas utilizando palavras compostas por sílabas simples e complexas e os estímulos utilizados foram palavras ditadas, figuras e palavras escritas. A estratégia de ensino estabeleceu relações entre estes estímulos e também envolveu a leitura oral e construção de palavras. Os testes de generalização incluíram a leitura e a escrita manuscrita de palavras e frases novas que apresentavam sílabas simples e complexas das palavras ensinadas.

Fonte: Dados organizados pelas autoras.

A seguir, descrevemos acerca das estratégias de ensino do programa Aprendendo a Ler e a Escrever em Pequenos Passos ${ }^{\circledR}$ utilizadas nas pesquisas de Afonso (2011), Freitas (2012), Menzori (2016) e Oliveira
(2010). Os Módulos do referido ProgLeit são estruturados em unidades de ensino. Os passos de ensino das unidades são divididos em atividades com treino da palavra inteira e treino silábico. A estratégia empregada nos passos de ensino envolve atividades por meio do conjunto de estímulos com palavra ditada, figura e palavra impressa. Estas atividades estabelecem conjuntos de respostas de nomeação oral (leitura) e escrita ou composição de palavras ou sílabas. As atividades consistem em selecionar: figura a partir de palavra ditada; palavra escrita a partir de palavra ditada; nomeação oral da figura; palavra escrita a partir da figura; figura a partir de palavra escrita; nomeação oral da palavra; ditado por composição; ditado manuscrito; cópia por composição e cópia manuscrita. Os testes de generalização incluem a leitura e a escrita de palavras resultantes da recombinação de sílabas que foram ensinadas.

Constatamos que cinco pesquisas voltadas à utilização de programas para o ensino de leitura e escrita aos estudantes com deficiência intelectual valeram-se de programas informatizados por meio de software educativo. Dentre elas, quatro pesquisas utilizaram o programa Aprendendo a Ler e a Escrever em Pequenos Passos® - ProgLeit (AFONSO 2011, FREITAS 2012, MENZORI 2016, OLIVEIRA 2010) e a pesquisa realizada por Santos (2012) utilizou o software educativo Mestre ${ }^{\circledR}$.

Participaram da pesquisa realizada por Freitas (2012) quatro estudantes com deficiência intelectual não alfabetizados, na faixa etária entre 9 a 12 anos. A autora considerou que o programa ProgLeit foi eficaz em preparar os estudantes para o ensino das tarefas de leitura e auxiliá-los a alcançar níveis mais elevados de compreensão da leitura.

Menzori (2016) utilizou o programa de ensino ProgLeit com nove estudantes com distúrbios da comunicação e/ou deficiência intelectual, entre 7 e 11 anos de idade, do $2^{\circ}$ ao $4^{\circ}$ ano do Ensino Fundamental e que frequentavam a sala de recursos multifuncionais. Sete estudantes finalizaram os passos do programa de ensino e obtiveram melhor desempenho na avaliação da leitura e escrita.

$\mathrm{Na}$ pesquisa realizada por Oliveira (2010) dois estudantes com deficiência intelectual matriculados no ensino fundamental em sala comum e em sala de recursos multifuncionais, em estágios de alfabetização diferentes $\left(2^{\circ}\right.$ e $5^{\circ}$ ano) utilizaram o programa ProgLeit. Os resultados indicaram a efetividade do programa para o ensino de leitura, tanto para as palavras simples quanto para aquelas mais complexas, podendo ser um recurso pedagógico complementar aos que são utilizados em sala de aula comum.

Afonso (2011) utilizou o programa ProgLeit com seis estudantes de uma escola especial, na faixa etária entre 14 a 26 anos, e seus familiares que realizavam com os estudantes, em suas residências, o treino das tarefas do Módulo 1 do referido programa. A pesquisadora concluiu que o ProgLeit pode ser uma situação promissora de aprendizagem, demonstrando a generalidade da aplicabilidade do programa para além do contexto laboratorial e escolar. 
Santos (2012) utilizou o software educativo Mestre ${ }^{\circledR}$ com cinco estudantes com deficiência intelectual, entre 15 e 21 anos, que frequentam uma escola de educação especializada (APAE). Constatou que o programa de ensino teve efeito positivo, pois houve melhora nos repertórios de leitura e escrita dos estudantes.

Conti (2014) desenvolveu o programa leitura compartilhada com dois estudantes com Síndrome de Down, na faixa etária entre 3 a 5 anos, que frequentavam um Centro Municipal de Educação Infantil. A pesquisadora concluiu que o referido programa de ensino possibilitou a promoção do letramento emergente em estudantes com deficiência intelectual na Educação Infantil.

Participaram da pesquisa desenvolvida por Brito (2014) seis jovens de 14 a 25 anos, com diagnóstico de deficiência intelectual, em momentos diferenciados na alfabetização. Os estudantes demonstraram facilidade em realizar as atividades de rima, aliteração e consciência de palavra. Evidenciaram dificuldade para realizar a leitura e a escrita das pseudopalavras. A pesquisadora concluiu que o melhor desempenho dos estudantes em algumas habilidades de consciência fonológica não auxiliou a habilidade de leitura e escrita e considerou que eles necessitavam de um período maior de intervenção.

\section{Tabela 4.}

Descrição das estratégias e recursos utilizados no ensino da leitura e escrita aos estudantes com deficiência intelectual

\begin{tabular}{l|l}
\hline Autor/Ano & \multicolumn{3}{|c}{ Estratégias/Recursos } \\
\hline Guebert & Exploração de texto literário (leitura de \\
(2013) & $\begin{array}{l}\text { livro): criar situação de suspense; instigar } \\
\text { discussão entre os estudantes sobre as }\end{array}$ \\
& possibilidades diante da situação vivenciada \\
& na história; ditado de palavras; cópia de \\
& frases; separação de sílabas e produção de \\
& texto a partir de imagem; criação de diálogo \\
& considerando o texto lido anteriormente; \\
& banco de palavras registrado na lousa pela \\
& professora; escrita espontânea e escrita como \\
& registro de atividades diárias.
\end{tabular}

Mesquita As atividades envolviam cores; numerais; (2015) letras do alfabeto com desenho, devendo ler a letra (nome) e desenho associado à letra, recortar, pintar e colar; contar histórias; cantar músicas; jogos pedagógicos convencionais e no computador. Os recursos utilizados eram a sala de informática; biblioteca; livros didáticos de Língua Portuguesa e Matemática com variações de gêneros e portadores textuais.

Tripiana- Exploração das diversas relações entre Barbosa palavra impressa, conjunto de letras, sílaba (2013) impressa, sílaba falada, figura, escrita manuscrita, palavra falada e soletração oral por meio do jogo de tabuleiro educativo AbraKedabra: construindo palavras - Souza, (2007). O objetivo do jogo consiste em o participante construir sua palavra impressa a partir das sílabas e emparelhar a palavra com a figura correspondente. O jogo tem início com a entrega de uma das palavras de ensino ao estudante e outra à pesquisadora. Foram utilizadas seis palavras de ensino como estímulos experimentais. As palavras de ensino eram dissílabas simples com correspondência entre grafemas e fonemas e sem dificuldades da língua.

Cruz Os recursos utilizados foram software de (2013) apresentação (PowerPoint), recursos da internet e Ambiente Virtual de Aprendizagem e Letramento (AVALER). As estratégias de ensino consistiram em roda de conversa inicial (discussão sobre assuntos ou leitura cooperativa), atividades no computador e roda de conversa final (apresentação das atividades elaboradas pelos estudantes de forma individual ou em duplas). As atividades realizadas no computador em slides eram a escrita de uma frase espontânea sem ajuda, a reescrita da frase com auxílio do professor e depois sem auxílio do professor. A internet foi utilizada para atividades de envio e recepção de e-mail, acesso a site de uma revista, vídeos/videoclipes.

Menezes As estratégias de ensino do gênero textual (2015) receita culinária por meio de uma sequência didática envolveram discussão oral, leitura colaborativa, escrita e reescrita das receitas culinárias produzidas pelos estudantes. Nas atividades de leitura foram utilizadas as estratégias de seleção, antecipação, inferência e verificação da leitura, a fim de auxiliar na compreensão do texto. Nas atividades de escrita e reescrita o foco da produção textual estava voltado para os elementos que estruturam e organizam o gênero textual receita culinária.

Segin Estratégia de ensino para o treino de (2015) habilidades fonológicas por meio do software Alfabetização Fônica Computadorizada (CAPOVILLA et al, 2005) e demais materiais como alfabeto móvel, blocos lógicos, lápis e papel. A estratégia consistiu em uma intervenção composta por 32 sessões individuais realizadas três vezes por semana. $\mathrm{Na}$ mesma sessão eram intercaladas as atividades do menu vogais, consciência fonológica e consoantes presentes no referido software. As atividades da consciência fonológica envolveram as habilidades em realizar a síntese silábica e fonêmica, rima, aliteração, segmentação silábica e fonêmica, manipulação silábica e fonêmica, transposição silábica e fonêmica.

Fonte: Dados organizados pelas autoras.

Constatamos diversidade nas estratégias de ensino e recursos pedagógicos voltados à leitura, escrita e letramento dos estudantes com deficiência intelectual. Entretanto, algumas pesquisas apontaram para a necessidade de se refletir acerca destas estratégias e recursos, a fim de adaptá-las para favorecer a participação e aprendizagem dos estudantes com deficiência intelectual durante as atividades de leitura e escrita propostas (GUEBERT 2013, SEGIN 2015).

Segin (2015) utilizou um software para o treino de habilidades fonológicas em 3 estudantes com Síndrome de Williams e 3 com Síndrome de Down, na faixa etária entre 9 e 11 anos, matriculadas no $3^{\circ}$ e $5^{\circ}$ ano do Ensino 
Fundamental. Os estudantes mantiveram a mesma classificação (muito baixa) nas avaliações pré e pósintervenção para todos os subitens da prova de consciência fonológica. A pesquisadora concluiu que a intervenção favoreceu o reconhecimento do nome das letras do alfabeto.

Guebert (2013) e Mesquita (2015) analisaram as estratégias de ensino utilizadas no processo de alfabetização de estudantes com deficiência intelectual matriculados, respectivamente, no $3^{\circ}$ e $1^{\circ}$ ano do Ensino Fundamental. Guebert (2013) concluiu que as estratégias de ensino utilizadas resultaram na aprendizagem da escrita de forma mecânica e, por esta característica, a relação entre conteúdo/forma trabalhada não favoreceu o desenvolvimento do letramento ao estudante. Em contrapartida, Mesquita (2015) expõe que as estratégias de ensino e recursos utilizados pelos professores, por meio do ensino colaborativo, com a estudante com deficiência intelectual demonstraram a contribuição para o desenvolvimento intelectual desta estudante, bem como, a importância da mediação do outro no processo de apropriação da leitura e da escrita e na participação da criança nas atividades propostas.

Corrobora a Mesquita (2015) o resultado das pesquisas realizadas por Cruz (2013), Menezes (2015) e Tripiana-Barbosa (2013) no que diz respeito ao fato das estratégias de ensino e recursos pedagógicos utilizados favorecerem a participação, o desenvolvimento e a aprendizagem destes estudantes.

\section{Conclusão}

Há poucas pesquisas nacionais sobre programas e estratégias de ensino desenvolvidas e utilizadas com os estudantes com deficiência intelectual para a produção escrita. Constatamos que algumas das estratégias e programas possibilitaram a este público-alvo da Educação Especial experimentarem a capacidade de ler e escrever com finalidades específicas, principalmente, no que diz respeito à habilidade de leitura. Desta forma, pela lacuna evidente nas produções científicas e pela dificuldade que estes estudantes demonstram no processo de alfabetização e escolarização sugerimos que futuras pesquisas desenvolvam estratégias ou programas de ensino que possam favorecer o desenvolvimento da escrita dos estudantes com deficiência intelectual.

\section{Referências}

AFONSO, P.B. (2011). Aplicação de um programa informatizado de ensino de leitura e escrita por familiares de indivíduos com deficiência intelectual. Dissertação, Mestrado em Psicologia, Universidade Federal de São Carlos, São Carlos, Brasil.

BARDIN, L. (2011). Análise de Conteúdo. São Paulo: Edições 70.

BRASIL. (2008). Ministério da Educação. Secretaria de Educação Especial. Política Nacional de Educação Especial na Perspectiva da Educação Inclusiva. Brasília: MEC/SEESP.

BRITO, D.A. (2014). Estimulando a consciência fonológica em jovens com deficiência intelectual.
Dissertação, Mestrado em Educação, Universidade do Estado do Rio de Janeiro, Rio de Janeiro, Brasil.

CONTI, L.M.C. (2014). Leitura partilhada e promoção de letramento emergente de pré-escolares com deficiência intelectual. Dissertação, Mestrado em Educação Especial, Universidade Federal de São Carlos, São Carlos, Brasil.

CRUZ, M.L.R.M. (2013). Ambiente virtual de aprendizagem para letramento de alunos com deficiência intelectual. Tese, Doutorado em Educação, Faculdade de Educação, Universidade do Estado do Rio de Janeiro, Rio de Janeiro, Brasil.

FREITAS, M.C. (2012). Construção de um programa de ensino de pré-requisitos de leitura e escrita para pessoas com deficiência intelectual. Tese, Doutorado em Psicologia, Universidade Federal de São Carlos, São Carlos, Brasil.

GUEBERT, M.C.C. (2013). Alfabetização de alunos com deficiência intelectual: um estudo sobre estratégias de ensino utilizadas no ensino regular. Tese, Doutorado em Educação, Pontifícia Universidade Católica de São Paulo, São Paulo, Brasil.

MEDRADO, C., GOMES, V.M. \& NUNES SOBRINHO, F.P. (2014). Atributos TeóricoMetodológicos da Revisão Sistemática das Pesquisas Empíricas em Educação Especial: evidências científicas na tomada de decisão sobre as melhores práticas inclusivas. En NUNES, L.R.O.P. (Ed.). Novas trilhas no modo de fazer pesquisa em Educação Especial. (pp.105-126). São Carlos: ABPEE.

MENEZES, M.A.A. (2015). Letramento e educação inclusiva: construindo práticas de leitura e escrita no ensino fundamental II. Dissertação, Mestrado em Letras, Universidade Federal de Sergipe, São Cristóvão, Brasil.

MENZORI, L.R.F. (2016). Ensino de leitura e escrita em crianças com diferentes necessidades educacionais especiais por meio de um programa informatizado de ensino. Dissertação, Mestrado em Psicologia do Desenvolvimento e Aprendizagem, Universidade Estadual Paulista Júlio de Mesquita Filho, Bauru, Brasil.

MESQUITA, G. (2015). O processo de alfabetização de uma criança com deficiência intelectual no $1^{\circ}$ ano do ensino fundamental. Dissertação, Mestrado em Educação, Universidade Federal do Espírito Santo, Vitória, Brasil.

OLIVEIRA, A.A.S. (2015). Avaliação da condição de alfabetização de estudantes com Deficiência Intelectual no contexto inclusivo. Arquivos Analíticos de Políticas Educativas/Education Policy Analysis Archives. Dossiê Educação Especial: Diferenças, Currículo e Processos de Ensino e Aprendizagem II. N.31, v.23, 31-48.

OLIVEIRA, G.P. (2010). Intervenção pedagógica individualizada para alunos com deficiência intelectual: ensino de leitura em salas de recursos. Tese, Doutorado em Educação Especial, Universidade Federal de São Carlos, São Carlos, Brasil.

OLIVEIRA, A.A.S. \& RUIZ, D.F.R. (2014). As práticas pedagógicas na área da deficiência intelectual e os 
processos de ensino e aprendizagem: análise da produção científica nacional. Plures. Humanidades. N.1, v.15, 30-51.

SANTOS, S.C.E. (2012). Ensino de leitura e escrita para aprendizes com deficiência intelectual. Dissertação, Mestrado em Educação, Pontifícia Universidade Católica de São Paulo, São Paulo, Brasil.

SEGIN, M. (2015). Alfabetização e deficiência intelectual: estudo sobre o desenvolvimento de habilidades fonológicas em crianças com Síndrome de Williams e Síndrome de Down. Tese, Doutorado em Distúrbios do Desenvolvimento, Universidade Presbiteriana Mackenzie, São Paulo, Brasil.

TRIPIANA-BARBOSA, A. (2013). O uso de um jogo de tabuleiro educativo no ensino de leitura e escrita a deficientes intelectuais. Dissertação, Mestrado em Análise do Comportamento, Universidade Estadual de Londrina, Londrina, Brasil.

VALENTIM, F.O.D. (2011). Inclusão de estudantes com deficiência intelectual: considerações sobre avaliação da aprendizagem escolar. Dissertação, Faculdade de Filosofia e Ciências, Universidade Estadual Paulista, Marília, Brasil.

\section{Agradecimentos}

Agência financiadora: Fundação de Amparo à Pesquisa do Estado de São Paulo (FAPESP). 